\title{
Development of Photoonycholysis with Vandetanib Therapy
}

\author{
Miruna Negulescu ${ }^{a} \quad$ Slimane Zerdoud ${ }^{b} \quad$ Serge Boulinguez ${ }^{a} \quad$ Emilie Tournier $^{c}$ \\ Jean-Pierre Delord ${ }^{d}$ Robert Baran ${ }^{\mathrm{e}}$ Vincent Sibaud ${ }^{\mathrm{a}, \mathrm{d}}$ \\ Departments of a Oncodermatology and ${ }^{b}$ Nuclear Medicine, Institut Claudius Regaud, Institut Universitaire \\ du Cancer ${ }^{\mathrm{C}}$ Department of Pathology, Institut Universitaire du Cancer, ${ }^{\mathrm{d}}$ Department of Medical Oncology and \\ Clinical Research, Institut Claudius Regaud, Institut Universitaire du Cancer, Toulouse Oncopole, Toulouse, and \\ e Department of Dermatology, Institut Gustave Roussy, Villejuif, France
}

\section{Established Facts}

- Photosensitivity reactions represent one of the most common adverse events described with vandetanib therapy, affecting more than one third of treated patients. A wide range of photoinduced skin manifestations has been individualized, including exaggerated sunburn reaction, blue dots, and hyperpigmentation or lichenoid photodermatitis.

\section{Novel Insights}

- Photoonycholysis has never been previously reported with vandetanib or with other anticancer targeted therapies.

\section{Keywords}

Vandetanib - Photosensitivity · Blue dots · Photoonycholysis . Reflectance confocal microscopy · Nail

\footnotetext{
Abstract

Vandetanib therapy is a novel once-daily oral multitargeted tyrosine kinase inhibitor, which is currently used in advanced or metastatic medullary thyroid cancer. Skin toxicities are among the most prevalent adverse events reported with this targeted therapy (e.g. acne-like rash, hand-foot skin reaction, hair changes, and paronychia). In addition, photosensi-
}

tivity reactions may affect more than one third of treated patients. We report here 2 patients developing photosensitivity reactions with vandetanib therapy, including photoonycholysis. Our patients presented a wide range of phototoxic reactions with exaggerated sunburn reactions solely located to photoexposed areas or hyperpigmentation with visible blue dots. More importantly, both patients concomitantly developed nail changes consistent with type 1 photoonycholysis, which had never been reported so far neither with vandetanib therapy nor with other anticancer-targeted therapies. In addition, histopathologic findings and reflectance confocal microscopy imaging performed in one pa-

\section{KARGER}

E-Mail karger@karger.com www.karger.com/sad (c) 2016 S. Karger AG, Basel

2296-9195/16/0024-0146\$39.50/0
Dr. Miruna Negulescu

Department of Dermatology, CHU Saint-Pierre Rue Haute 322

BE-1000 Bruxelles (Belgique)

E-Mail miruna_negulescu@ stpierre-bru.be 
Table 1. Skin toxicity profile of vandetanib

Median \% of patients (range)

$\begin{array}{lc}\text { Skin adverse events related to EGFR pathway inhibition }[1,5,6] & 49(20-78) \\ \text { Papulopustular eruption } & 18(15-21) \\ \text { Dry skin } & 11 \\ \text { Paronychia } & 5 \\ \text { Finger clefts } & 5 \\ \text { Hypertrichosis } & 11 \\ \text { Pruritus } & 8 \\ \text { Skin adverse events related to VEGFR pathway inhibition [6] } & 5 \\ \text { Hand-foot skin reaction } & 5 \\ \text { Subungual splinter hemorrhages } & \\ \text { Scalp dysesthesia } & 20(4-37)[5,6] \\ \text { Vandetanib-related photosensitivity reactions } & 19[6,10,17] \\ \text { Photosensitivity reactions (exaggerated sunburn response, sunburn-like reaction, } \\ \text { burning sensation; erythema, edema } \pm \text { blisters on photoexposed areas, etc.) } & 2 \text { case reports }[6,17] \\ \text { Well-demarcated hyperpigmentation and blue dots } & 1 \text { single case report [6] } \\ \text { Erythema multiforme } & 11 \text { case reports [6-9,11] } \\ \text { Subacute cutaneous lupus erythematosus } & 2 \text { patients (belonging to our case series) } \\ \text { Photodistributed lichenoid eruption } & \end{array}$

EGFR, epidermal growth factor receptor; VEGFR, vascular endothelial growth factor receptor.

tient suffering from photodistributed skin hyperpigmentation both strengthen the likelihood of a postinflammatory mechanism. Clinicians should be aware of these underestimated but very characteristic photoinduced adverse events, which can lead to treatment interruption and require very strict photoprotective measures in treated patients.

(c) 2016 S. Karger AG, Basel

\section{Introduction}

Vandetanib is a novel orally available multikinase inhibitor targeting either epidermal growth factor receptor, vascular endothelial growth factor receptor, or rearranged during transfection proto-oncogene $[1,2]$. This targeted therapy is now FDA- and EMA-approved for patients with locally advanced or metastatic medullary thyroid carcinoma $[1,3]$. Although vandetanib therapy exhibits a favorable risk/benefit profile, systemic toxicities are common, including diarrhea, QTc prolongation, fatigue, and hypertension $[4,5]$. Skin toxicities are also among the most prevalent adverse events and appear to be strictly related to the direct inhibition of targeted pathways in the skin and appendages [1]. Indeed, dermatologic adverse events occur in a large majority of treated patients, mainly in the form of papulopustular rash, hand-foot skin reaction, dry skin, hair changes, and periungual lesions (i.e., paronychia, pyogenic granuloma) [1, 2, 6] (Table 1).

Vandetanib, which is a low-molecular-weight molecule with a polycyclic structure containing unsaturated double bonds, can also induce photosensitivity reactions $[1,2,5,6]$. Recently, a prospective study reported that photosensitivity reactions affected more than a third of patients, including severe reactions that had led to treatment interruption in roughly $15 \%$ of cases [6]. However, photoinduced manifestations of vandetanib have been described only sporadically to date, and dermatologic data on this topic remain scarce $[1,5-11]$.

We describe here 2 patients who developed a wide range of photosensitivity reactions with vandetanib therapy, including photoonycholysis, which has never been previously reported with this drug.

\section{Case Reports}

Patient No. 1

A 70-year-old patient was treated with $300 \mathrm{mg}$ once-daily vandetanib for metastatic medullary thyroid cancer. Two months after treatment initiation, he presented with a grade 1 photodistributed erythematous eruption involving the face and dorsal aspect of the hands (according to the National Cancer Institute, NCI-CTCae 


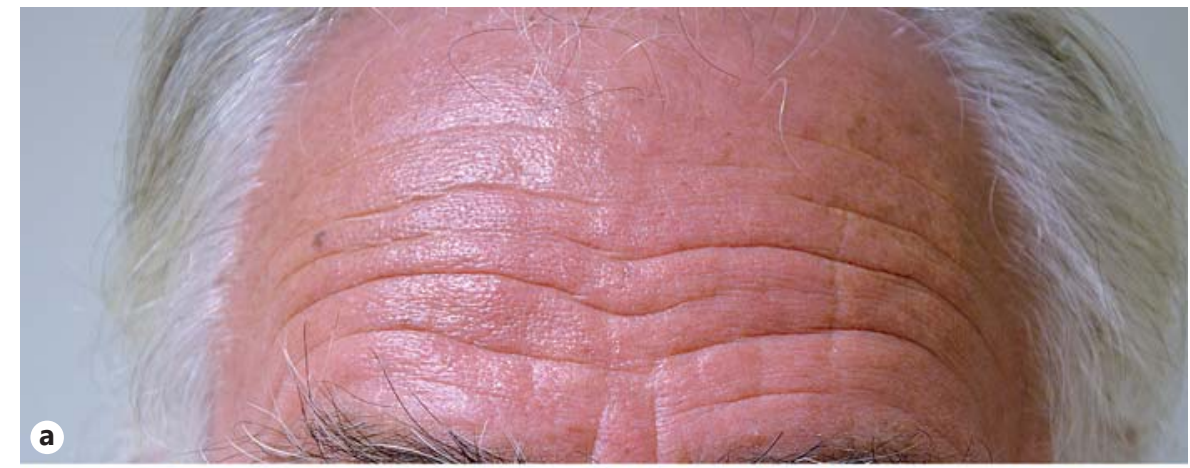

Fig. 1. a Grade 1 cutaneous photosensitivity reaction (forehead). b, c Typical type I photoonycholysis of all fingernails (with characteristic sparing of lateral margins of the nail plate); pigmentation of left forefinger and right middle and ring fingers with splinter hemorrhages; note the yellowish discoloration of all fingernails secondary to a Pseudomonas aeruginosa superinfection. d Despite vandetanib continuation, significant clinical improvement after 3 months of intense sun protection.
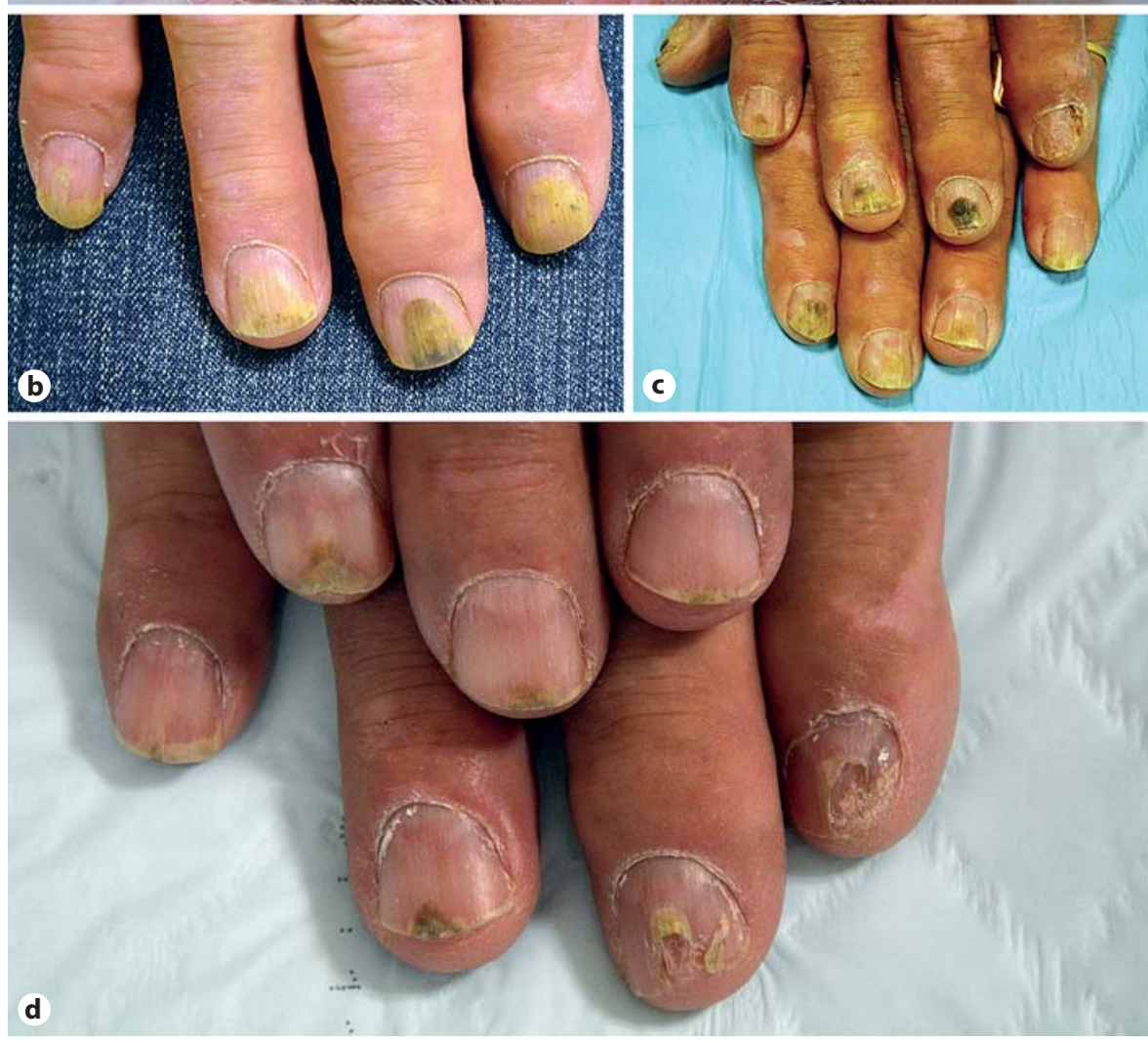

V4.02) (Fig. 1a). One month later, he developed mildly painful medial onycholysis involving all the fingernails. Conversely, the photoprotected toenails were not involved. Clinical examination revealed yellowish distal onycholysis and splinter hemorrhages, highly suggestive of a type 1 photoonycholysis typically sparing the lateral margins of the nail plate (Fig. 1b, c). Treatment was continued and photoprotective measures were advised. At the same time, the central onycholytic nail plates were clipped away. After 3 months of intense sun protection (gloves), a clinical improvement of the nail lesions was noted (Fig. 1d).

\section{Patient No. 2}

Three months after vandetanib initiation for metastatic medullary thyroid cancer, a 42-year-old patient was referred to our dermatology department with the recent occurrence of moder- ately painful nail lesions. Clinical examination revealed medial onycholysis of both thumbs (Fig. 2a) associated with a wide median erythematous strip on each of the other fingernails (Fig. 2b). Early distal onycholysis of both forefingers was also identified (Fig. 2b). Type 1 photoonycholysis was diagnosed. The patient also presented with a grade 1 papulopustular eruption involving the central part of the face and upper trunk. Finally, he exhibited a diffuse dusty blue-gray pigmentation over the whole face, the dorsal aspect of the hands and the neck, with visible blue dots (Fig. 2c). Hyperpigmented lesions were strictly confined to photoexposed skin with well-demarcated borders adjacent to sunprotected areas. These pigmentary changes developed progressively after 2 months of vandetanib therapy. Prior to the progressive development of hyperpigmentation, the patient had had recurrent episodes of acute grade 2 photosensitivity in the form of 
Fig. 2. a Photoonycholysis of both thumbs with well-demarcated proximal borders. b Wide median erythematous strip involving all fingernails, suggestive of hemorrhagic scattering; mild onycholysis of forefinger. c Blue-gray dusty hyperpigmentation sparing nonexposed areas, associated with visible blue dots (see white arrows). d Pigment incontinence with melanophages visible in the upper papillary dermis (hemalum-eosin stain; original magnification $\times 40)$. e Reflectance confocal microscopy (using a MAVIG Vivascope 1500) aspects with plump bright cells in the dermis (melanophages).
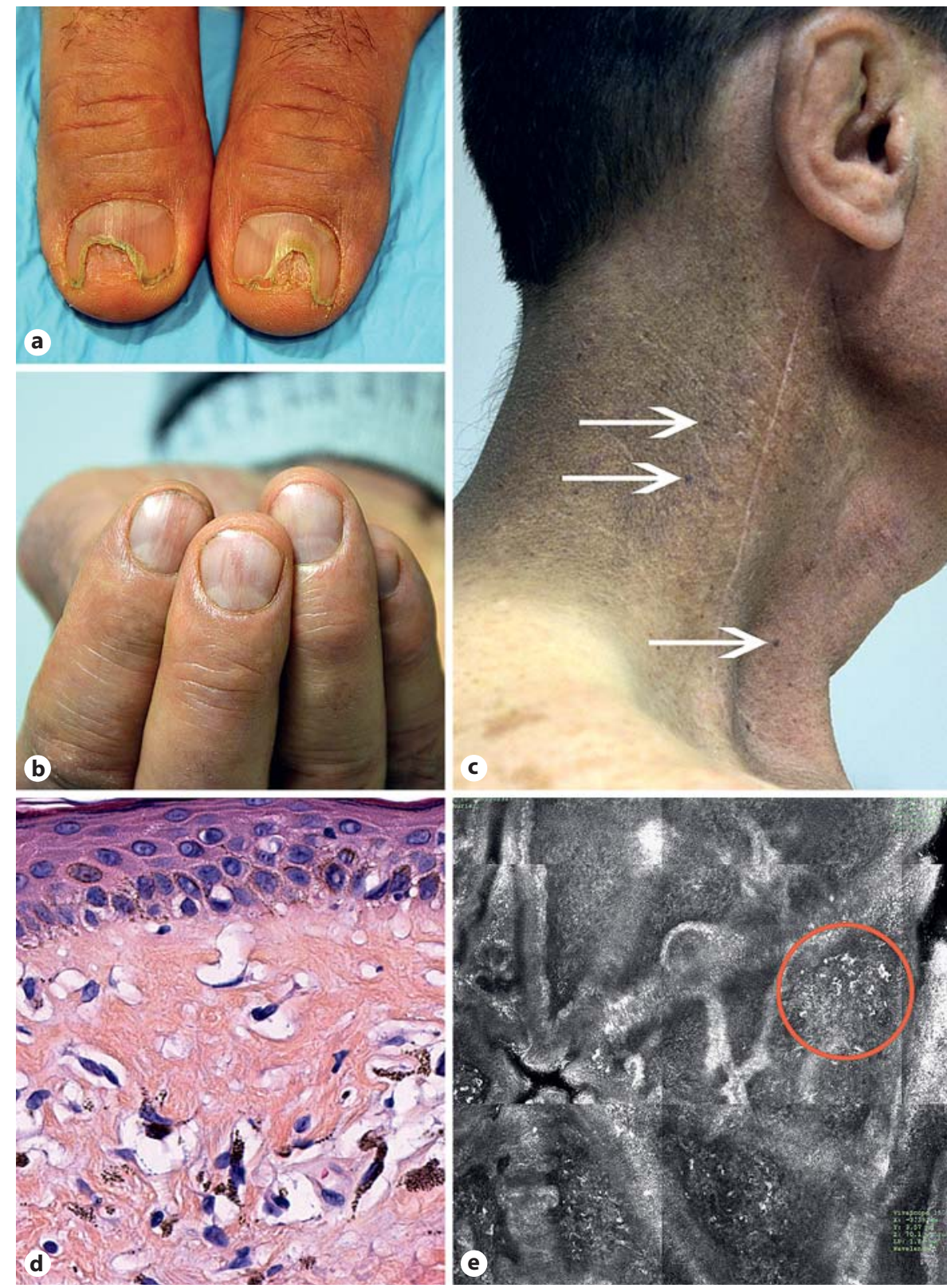

pruritic erythematous plaques, which were strictly localized to the same anatomic areas. Histologic examination with melanin staining of a skin biopsy specimen demonstrated marked melanin incontinence with the presence of numerous melanophages in the superficial dermis (Fig. 2d). Reflectance confocal microscopy (using a MAVIG Vivascope 1500) of hyperpigmented lesions isolated numerous plump bright cells in the dermis corresponding to melanophages (Fig. 2e). Vandetanib therapy was maintained and the hyperpigmented lesions faded gradually. The photoonycholytic lesions improved progressively with strict photoprotective education.

Photoonycholysis with Vandetanib Therapy

\section{Discussion}

Photosensitivity reactions are a common toxicity of vandetanib therapy, affecting more than a third of treated patients with $4-26 \%$ of grade $\geq 3$, which can lead to treatment discontinuation $[5,6]$. Along with the BRAF inhibitor vemurafenib, vandetanib is clearly the anticancer tyrosine kinase inhibitor most frequently involved in the induction of photosensitivity reactions [12].

The most common form is an acute inflammatory photosensitivity reaction, which remains strictly limited 
to sun-exposed areas, as shown by our two patients. Several days or weeks after treatment initiation, photosensitivity can manifest as an exaggerated sunburn response, a burning sensation, or a more severe reaction with edema and blister formation $[6,9,13]$. The clinical presentation of a vandetanib-induced photosensitivity reaction is suggestive initially of a phototoxic mechanism [14]. However, several late-onset reactions have also been reported and a photoallergic origin cannot be totally ruled out [7, $11,13]$. Sporadic reports of photosensitivity occurring through window glass-filtered sunlight suggest that UVA radiation is the main triggering factor $[2,6]$. In the same way, available in vitro data are also in favor of a phototoxic UVA-based mechanism [15]. Indeed, Salvador et al. [15] recently demonstrated in a human keratinocyte cell line irradiated with UVA that vandetanib itself induced a dose-dependent phototoxic mechanism. It has been postulated that this phototoxic damage could be mediated by the formation of a very reactive species (aryl radical) inducing a secondary interaction with DNA and cell apoptosis [15]. Conversely, photoproducts obtained after the loss of a vandetanib bromine atom following UVA photodegradation did not contribute to this phototoxic reaction [15]. Furthermore, well-demarcated skin hyperpigmentation is also commonly observed in roughly $20 \%$ of patients treated with vandetanib therapy [6-10]. Different types of isolated or combined hyperpigmentation can be seen: blue-gray hyperpigmentation, diffuse brown pigmentation, or, as reported in our second patient, perifollicular dark blue-gray macules in the form of blue dots, which are the most characteristic pigmentary changes observed with vandetanib therapy $[10,12,16]$. In all cases, these pigmentary changes remain strictly confined to UV-exposed skin areas with clear borders with non-photoexposed skin. Vandetanib-related hyperpigmentation mainly develops following inflammatory photosensitivity $[6-9,11]$ or acne-like reactions $[10]$, as in our second patient. Nevertheless, hyperpigmentation was associated with a prior or concomitant photosensitivity reaction in only $50 \%$ of patients in the prospective series of Giacchero et al. [6]. This might be due, at least in part, to unnoticed low-grade photosensitivity reactions [6]. The pathophysiology of vandetanib-induced skin hyperpigmentation remains unclear, but it may be caused by accumulation of the drug, drug metabolites, iron, or complexes of drug and melanin in the skin $[10,12]$. Melanin incontinence with the presence of melanophages in the dermis is, however, the most frequent histopathologic change reported in this context [7-9, 11]. In the same way, reflectance confocal microscopy imaging performed in our second pa- tient was consistent with these histopathological findings. These features strengthen the likelihood of a postinflammatory origin in most cases.

More specific photoinduced manifestations have also been described with vandetanib therapy, including a single observation of subacute cutaneous lupus erythematosus [6] or several cases of lichenoid photodermatitis [6-8, 11] (Table 1). Likewise, photodistributed erythema multiforme has been previously described in two patients $[6$, 17]. Phototesting performed by Caro-Gutiérrez et al. [17] showed a reduced minimal erythema dose for UVA $(<1$ $\mathrm{J} / \mathrm{cm}^{2}$ ) without modifications in UVB phototests.

We report here two cases of typical photoonycholysis induced by vandetanib therapy, which has never been previously described to the best of our knowledge. Photoonycholysis represents an unusual manifestation of acute phototoxicity [14]. It can occur following drug intake but also with different forms of porphyria or pseudoporphyria [18]. Tetracycline derivatives, psoralens, fluoroquinolones, and, less commonly, chloramphenicol, oral contraceptives, chlorpromazine, voriconazole, thiazide diuretics, and griseofulvin are the most frequently incriminated drugs [18-21]. However, photoonycholysis has never been previously reported with anticancer-targeted therapies [22]. Photoonycholysis generally develops several weeks after a phototoxic skin manifestation [18], as in our two patients. Nevertheless, it can also appear independently, without any preexisting cutaneous phototoxic reaction [18]. Four types are individualized, without apparent relationship with the causative drug [18]. Our two patients exhibited the most common form, type 1 photoonycholysis, which typically involves several fingernails together and leads to a very suggestive halfmoon-shaped appearance sparing the lateral parts of the nail plate [18]. Several reasons may be advanced to explain why fingernails represent a privileged target for photodamage: firstly, the nail plays the role of a convex lens, focusing UV rays; secondly, nail bed melanin is reduced and does not provide strong protection against UV radiation; thirdly, the absence of stratum granulosum and sebaceous glands in the subungual area may not prevent UV transmission $[14,19]$. This nail complication is usually painful, as noted in our patients [19]. The etiology is unknown, but capillaries, terminal vessels, and glomus bodies could be involved in this symptom $[18,19]$.

In conclusion, vandetanib can induce a wide spectrum of photosensitivity reactions and patients should be closely monitored accordingly. This should also include a systematic examination of fingernails. Patients should receive strict instruction about photoprotection from the 
initiation of vandetanib therapy, including the avoidance of direct sunlight, protective clothing and nail polish, and broad-spectrum UVB/UVA sunscreens. In addition, photoprotective measures should be maintained throughout the duration of treatment because late-onset UV-induced reactions may also appear with vandetanib therapy $[6,11]$. This can improve patient's health-related quality of life and promote treatment compliance by restricting dose-limiting toxicities.

\section{Statement of Ethics}

The authors certify that each subject included in this article completed a written consent before pictures and biopsy.

\section{Disclosure Statement}

No conflict of interest or funding sources are declared.

\section{References}

1 Lacouture ME, Ciccolini K, Kloos RT, Agulnik M: Overview and management of dermatologic events associated with targeted therapies for medullary thyroid cancer. Thyroid 2014;24:1329-1340.

2 Grande E, Kreissl MC, Filetti S, Newbold K, Reinisch W, Robert C, Schlumberger M, Tolstrup LK, Zamorano JL, Capdevila J: Vandetanib in advanced medullary thyroid cancer: review of adverse event management strategies. Adv Ther 2013;30:945-966.

3 Caprelsa - vandetanib.pdf. Available at: http://www1.astrazeneca-us.com/pi/vandetanib.pdf. Accessed January 9, 2016.

4 Wells SA, Robinson BG, Gagel RF, Dralle H, Fagin JA, Santoro M, Baudin E, Elisei R, Jarzab B, Vasselli JR, Read J, Langmuir P, Ryan AJ, Schlumberger MJ: Vandetanib in patients with locally advanced or metastatic medullary thyroid cancer: a randomized, double-blind phase III trial. J Clin Oncol 2012;30:134-141.

5 Leboulleux S, Bastholt L, Krause T, de la Fouchardière C, Tennvall J, Awada A, Gomez JM, Bonichon F, Leenhardt L, Soufflet C, Licour M, Schlumberger MJ: Vandetanib in locally advanced or metastatic differentiated thyroid cancer: a randomised, double-blind, phase 2 trial. Lancet Oncol 2012;13:897-905.

6 Giacchero D, Ramacciotti C, Arnault JP, Brassard M, Baudin E, Maksimovic L, Mateus C, Tomasic G, Wechsler J, Schlumberger M, Robert C: A new spectrum of skin toxic effects associated with the multikinase inhibitor vandetanib. Arch Dermatol 2012;148:1418-1420.
7 Fava P, Quaglino P, Fierro MT, Novelli M, Bernengo MG: Therapeutic hotline. A rare vandetanib-induced photo-allergic drug eruption. Dermatol Ther 2010;23:553-555.

8 Son YM, Roh JY, Cho EK, Lee JR: Photosensitivity reactions to vandetanib: redevelopment after sequential treatment with docetaxel. Ann Dermatol 2011;23:S314-S318.

9 Chang $\mathrm{CH}$, Chang JWC, Hui CY, Yang $\mathrm{CH}$ : Severe photosensitivity reaction to vandetanib. J Clin Oncol 2009;27:e114-e115.

10 Kong HH, Fine HA, Stern JB, Turner MLC: Cutaneous pigmentation after photosensitivity induced by vandetanib therapy. Arch Dermatol 2009;145:923-925.

11 Bota J, Harvey V, Ferguson C, Hood A: A rare case of late-onset lichenoid photodermatitis after vandetanib therapy. J Am Acad Dermatol 2015;1:141-143.

12 Sibaud V, Robert C: Pigmentary disorders induced by anticancer agents. Part II: targeted therapies. Ann Dermatol Venereol 2013;140: 266-273.

13 Goldstein J, Patel AB, Curry JL, Subbiah V, Piha-Paul S: Photoallergic reaction in a patient receiving vandetanib for metastatic follicular thyroid carcinoma: a case report. BMC Dermatol 2015;15:1-5.

14 Gould JW, Mercurio MG, Elmets CA: Cutaneous photosensitivity diseases induced by exogenous agents. J Am Acad Dermatol 1995; 33:551-573.
15 Salvador A, Vedaldi D, Paola B, Dall'Acqua S: Vandetanib-induced phototoxicity in human keratinocytes NCTC-2544. Toxicol In Vitro 2014;28:803-811.

16 Brooks S, Linehan WM, Srinivasan R, Kong $\mathrm{HH}$ : Successful laser treatment of vandetanibassociated cutaneous pigmentation. Arch Dermatol 2011;147:364-365.

17 Caro-Gutiérrez D, Floristán Muruzábal MU, Gómez de la Fuente E, Franco AP, López Estebaranz JL: Photo-induced erythema multiforme associated with vandetanib administration. J Am Acad Dermatol 2014;71:e142e144.

18 Baran R, Juhlin L: Photoonycholysis. Photodermatol Photoimmunol Photomed 2002; 18: 202-207.

19 Baran R, Juhlin L: Drug-induced photo-onycholysis: three subtypes identified in a study of 15 cases. J Am Acad Dermatol 1987;17: 1012-1016.

20 Chandran NS, Aw DCW: Drug-induced photo-onycholysis: an often-neglected phenomenon. Intern Med J 2013;43:1349-1350.

21 Willis ZI, Boyd AS, Di Pentima MC: Phototoxicity, pseudoporphyria, and photo-onycholysis due to voriconazole in a pediatric patient with leukemia and invasive aspergillosis. J Pediatr Infect Dis Soc 2015;4:e22-e24.

22 Robert C, Sibaud V, Mateus C, Verschoore M, Charles C, Lanoy E, Baran R: Nail toxicities induced by systemic anticancer treatments. Lancet Oncol 2015;16:e181-e189. 